\title{
A Conquista do direito ao casamento LGBTI+: da Assembleia Constituinte à Resolução do CNJ.
}

The conquer of LGBTI+ marriage right: since Constituent Assembly until CNJ's Resolution.

\section{Ivanilda Figueiredo'}

${ }^{1}$ Universidade do Estado do Rio de Janeiro, Rio de Janeiro, Rio de Janeiro, Brasil. E-mail: ivanilda.figueiredo@gmail.com. ORCID: https://orcid.org/0000-0002-6100-7834.

Artigo recebido em 18/06/2020 e aceito em 11/01/2021.

\section{(cc) $\mathrm{EY}$}

This work is licensed under a Creative Commons Attribution 4.0 International License. 
Resumo

A Constituição de 1988 determinou que a união estável seria apenas entre homem e mulher. O Código Civil de 2003 fez a mesma determinação para o casamento. Até ali não existiam normas jurídicas proibindo uniões entre pessoas do mesmo gênero, nem tampouco as reconhecendo. Partindo dessas ausências (demandas suprimidas) e normatizações, apresentaremos o esforço para a conquista do direito ao casamento LGBT por meio de estratégias parlamentares e judiciais que maturaram o debate público e garantiram a vitória.

Palavras-chaves: Casamento LGBTI+; Processo legislativo; Supremo Tribunal Federal.

\section{Abstract}

The 1988 Constitution determined that the common-law marriage would be between men and women only. The 2003 Civil Code made the same determination for marriage. Until then, there were no legal rules prohibiting unions between people of the same gender, nor did they recognize them. Based on these absences (suppressed demands) and norms, we will present the effort to conquer the right to LGBT marriage through parliamentary and judicial strategies that matured the public debate and guaranteed victory.

Keywords: LGBTI+ marriage; Legislative process; Brazil's Supreme Court. 
Introdução

Quem tem o direito de dizer com quem duas pessoas adultas podem contrair matrimônio? Formar uma família? O casamento entre pessoas brancas e negras era proibido na África do Sul entre 1949 e1985; e em 16 estados do Estados Unidos da América até 1967, quando a Suprema Corte julgou o caso Loving versus Virginia e considerou inconstitucionais todas estas leis ${ }^{2}$.

Tais normas jurídicas não impediram que inúmeros casais se formassem e vivessem o amor e o afeto em segredo. John Blacking, professor universitário branco, e Zureena Desai, médica negra, foram condenados em 1969 na África do Sul quando o relacionamento entre eles foi descoberto. Fugindo da perseguição, passaram a viver na Inglaterra, onde casaram e tiveram quatro filhos. ${ }^{3}$

Mildred e Richard Loving viajaram da Virginia para Washington, onde não existia proibição ao casamento interracial, para oficializar a relação. No retorno para casa, foram processados e condenados a um ano de prisão com direito a suspensão da pena se fossem embora da Virginia e não voltassem pelos próximos 25 anos. O casal deixou o estado, mas em 1964 - por não poderem visitar familiares, dada a condenação - iniciaram o processo judicial que viria a tornar inconstitucional a perseguição aos relacionamentos interraciais. ${ }^{4}$

Terry Donahue e Pat Henschel viveram juntas por 72 anos, tendo iniciado o namoro na década de 40 nos Estados Unidos. ${ }^{5}$ Naquele período, o relacionamento entre pessoas do mesmo gênero ainda era ilegal em grande parte do país e mais de cinco mil funcionários públicos foram demitidos apenas por serem homossexuais nos anos seguintes. ${ }^{6}$

Já Edith Windsor e Thea Spyer iniciaram o relacionamento na década de 60 e viveram juntas por 42 anos até oficializarem a união no Canadá antes de Thea, que já

\footnotetext{
${ }^{1}$ SOUTH AFRICA. Prohibition of Mixed Marriages e Immorality Act, ambas leis de 1949. A primeira proibia o casamento, a segunda as relações sexuais. Disponível em: https://www.sahistory.org.za/datedevent/prohibition-mixed-marriages-act-commences Acesso em 09 de junho de 2020.

2 UNITED STATES. Supreme Court. Decisão na íntegra disponível em: https://www.oyez.org/cases/1966/395 Acesso em: 09 de junho de 2020.

3 Disponível em: https://www.cambridge.org/core/services/aop-cambridgecore/content/view/S0261143000004463 Acesso em: 09 de junho de 2020

${ }^{4}$ Idem nota 2

${ }^{5}$ A SECRET LOVE (documentário). Diretor: Chris Bolan. Produtora: Netfox, USA, 2020.

6 FIGUEIREDO, Ivanilda. Terror Colorido. Disponível em: https://oglobo.globo.com/opiniao/artigo-terrorcolorido-24433466 Acesso em: 29 de maio de 2020
} 
estava doente há longos anos, falecer. Ambas foram ativistas pelos direitos LGBTI+ durante toda a vida. Quando da morte de Thea, Edith teve seus bens de herança taxados de forma desproporcional, pois diante da lei não eram um casal. Tal fato a levou a processar o governo federal e obter decisão da Suprema Corte considerando inconstitucional a lei de defesa do casamento (Defense of Marriage Act-DOMA). ${ }^{7}$

No Brasil, nunca houve uma lei que proibisse os casamentos interraciais ${ }^{8}$, embora o racismo estrutural seja um dimensionador de como estas relações foram (e são) vivenciadas ou impedidas ao longo dos anos. ${ }^{9}$ Já o casamento entre pessoas do mesmo gênero era considerado um ato jurídico nulo até 2011, quando Katia Ozório e Leticia Perez foram autorizadas a emitir os proclamas de seu casamento pelo Superior Tribunal de Justiça (STJ). ${ }^{10}$

Em comum a todas estas histórias, há, por um lado, a interdição do Estado em não reconhecer a união de duas pessoas adultas como válida e, por outro, a luta dessas pessoas, que são representativas da ausência de direitos e do silenciamento de milhares de casais ao longo dos anos para obter o reconhecimento legal de seus relacionamentos.

São, portanto, um exemplo de como direitos fundamentais são conquistas realizadas por diferentes pessoas e grupos em articulações políticas e jurídicas responsáveis por mudanças sociais, legislativas e judiciais.

Este estudo pretende rememorar o longo caminhar para a aprovação do casamento LGBTI+ no Brasil, por meio das lutas travadas desde a Constituinte até a Resolução 175/2013 do Conselho Nacional de Justiça a partir da qual restou "vedada às autoridades competentes a recusa de habilitação, celebração de casamento civil ou de conversão de união estável em casamento entre pessoas de mesmo sexo".

Desde a aprovação do casamento LGBTI+ no Brasil, há inúmeros textos acadêmicos de grande importância detalhando as teses judiciais utilizadas. ${ }^{11}$ Vários deles serão referenciados ao longo da análise, mas não é nosso objetivo aprofundar este

\footnotetext{
7 UNITED STATES. Supreme Court. United States versus Windsor. Decisão na integra: https://www.supremecourt.gov/opinions/12pdf/12-307_6j37.pdf Acesso em: 29 de maio de 2020

${ }^{8}$ CUNHA, M. F. (2017). Casamentos mistos: entre a escravidão e a liberdade. Franca-São Paulo/Brasil, século XIX. Revista Brasileira De Estudos De População, 34(2), 223-242. https://doi.org/10.20947/S0102-3098a0022 ${ }^{9}$ Sobre o racismo estrutural, recomenda-se ALMEIDA, Silvio. Racismo Estrutural. 1. ed. São Paulo/ Brasil: Pólen Livros, 2019. 256p.

10 BRASIL Superior Tribunal De Justiça. RESP 1.183.378/RS Disponível em: https://www.conjur.com.br/dl/resp-1183378-voto-relator-julgamento.pdf Acesso em: 16 de junho de 2020. 11 VECHIATTI, Paulo Robert lotti. Manual da Homoafetividade; São Paulo: Método, 2013, p. 158-161. Moreira, A. J. Cidadania Sexual: Estratégia para Ações Inclusivas. 1. ed. São Paulo: Arraes Editores, 2017. v. 1. pp. 153226
} 
aspecto. Nossa pretensão é descortinar uma abordagem inédita que conjuga os aspectos políticos e jurídicos da luta por este direito ${ }^{12}$, demonstrando que quando o tema chegou ao STF via controle concentrado de constitucionalidade já existia um longo caminhar no Congresso Nacional e na jurisprudência.

Este artigo apresentará, em princípio, a etapa da união estável LGBTI+ como uma demanda suprimida. Boaventura de Souza Santos, ao tratar de uma sociologia das ausências, cria o termo "procura suprimida" para designar a falta de postulação judicial por determinadas pessoas ou grupos de seus direitos. ${ }^{13}$ Falamos, então, "demanda suprimida" para designar a ausência - por contingências socioculturais e históricas- de apresentação de uma demanda por direitos. Tanto os casais LGBTI+s já existiam quanto o próprio movimento já estava organizado em 1987, entretanto a demanda pelo direito à união estável LGBTI+ não esteve presente na Constituinte, como se demonstrará no item 01

Em sequência, demonstraremos os debates legislativos e judiciais se entrecruzando enquanto atores políticos voluntários (ativistas, parlamentares aliados, etc.) e involuntários (pessoas LGBTI+ que precisaram por contingências práticas da realidade buscar as vias judiciais para obter direitos) lutam por uma arena na qual seus clamores ressoem e seus direitos sejam assegurados.

1. Da "demanda suprimida" na Constituinte aos diversos projetos de lei sobre o tema

O debate na Assembleia Constituinte em torno do rol de direitos fundamentais a serem expressos constitucionalmente foi extremamente rico. O movimento LGBTI+ participou apresentando a demanda de proibição da discriminação por orientação sexual e, apesar

\footnotetext{
12 existiram importantes ativistas e movimentos pró-direitos LGBTI+ desde as décadas de 1960/1970, especialmente organizados no Rio de Janeiro (Triângulo Rosa) e São Paulo (Somos, Grupo de Ação Lésbica Feminista). Alguns ativistas como Cassandra Rios e Herbert Daniel foram candidatos a deputados estaduais em 1986, mas não foram eleitos. Na prática, o tema só passou a ser pautado diante das instituições do Estado a partir da Constituinte.

${ }^{13}$ SANTOS, Boaventura de Souza. Para uma Revolução Democrática da Justiça. São Paulo: Cortez, 2007, p. 23
} 
de aprovar a proposta em duas Subcomissões constituintes ${ }^{14}$, não logrou sua inclusão no texto final.

Importante rememorar que, numa eleição permeada por marcas e limitações do processo de redemocratização, foram eleitos os parlamentares da Assembleia Nacional Constituinte (ANC) a qual, após finda a redação do texto constitucional, permaneceria como Congresso Nacional.

Em 1ำ de fevereiro de 1987, sob a presidência do ministro José Carlos Moreira Alves, presidente do Supremo Tribunal Federal, instalou-se, em sessão solene, a Assembleia Nacional Constituinte ${ }^{15}$ com 559 parlamentares, sendo 512 deputados $^{16}$ e 55 senadores eleitos. ${ }^{17} \mathrm{Na}$ primeira sessão ordinária, por 394 a favor, 124 contra e 17 abstenções, venceu que seriam também parte no novo Congresso 26 Senadores "biônicos", ou seja, Senadores não eleitos que haviam sido nomeados pelo ditador Ernesto Geisel. Em seguida, Ulisses Guimarães foi escolhido Presidente da ANC. ${ }^{18}$

Rejeitou-se a ideia de se principiar a redação tendo como base um anteprojeto, assim os debates iniciaram a partir da divisão em Comissões e Subcomissões temáticas. ${ }^{19}$ Forças conservadoras, que eram ampla maioria, e progressistas travaram inúmeros embates neste processo. Intensa também foi a participação dos cidadãos, movimentos sociais, organizações da sociedade civil, religiões (especialmente a católica), empresários, ruralistas e demais forças sociais nas Subcomissões, por meio das audiências públicas e em sugestões de textos enviados para as Comissões. ${ }^{20}$

Nessa etapa, a participação dos constituintes e da população foi intensa, tendo sido concedidas 182 audiências públicas, encaminhadas 11.989 propostas e apresentadas 6.417 emendas aos anteprojetos. A sobrecarga de

\footnotetext{
${ }^{14}$ Subcomissão de Direitos e Garantias Individuais da Comissão da Soberania e dos Direitos e Garantias do Homem e da Mulher e na Subcomissão dos Negros, Populações Indígenas, Pessoas Deficientes e Minorias da Comissão da Ordem Social.

15 CPDOC/FGV. Disponível em: http://www.fgv.br/cpdoc/acervo/dicionarios/verbete-tematico/assembleianacional-constituinte-de-1987-88 Acesso em: 20 de junho de 2019

16 BRASIL Câmara dos Deputados. Disponível em: https://www2.camara.leg.br/atividadelegislativa/legislacao/Constituicoes_Brasileiras/constituicao-

cidada/constituintquees/parlamentaresconstituintes/deputados-constituintes Acesso em: 20 de junho de 2019

17 BRASIL. Câmara dos Deputados. Disponível em: https://www2.camara.leg.br/atividadelegislativa/legislacao/Constituicoes_Brasileiras/constituicao-

cidada/constituintes/parlamentaresconstituintes/senadores-constituintes Acesso em: 20 de junho de 2019

$18 \mathrm{CPDOC} / \mathrm{FGV}$. Disponível em: http://www.fgv.br/cpdoc/acervo/dicionarios/verbete-tematico/assembleianacional-constituinte-de-1987-88 Acesso em: 20 de junho de 2019

19 BRASIL. Câmara dos Deputados. Disponível em: https://www2.camara.leg.br/atividadelegislativa/legislacao/Constituicoes_Brasileiras/constituicao-cidada/o-processo-constituinte/lista-decomissoes-e-subcomissoes Acesso em: 22 de junho de 2019.

20 Disponível em: https://www.senado.leg.br/publicacoes/anais/constituinte/fontes.pdf Acesso em: 10 de junho de 2020
} 
informações e de temas, a inexperiência de parte dos parlamentares e normas regimentais novas e imprecisas produziram algumas votações confusas. Por sua vez, o procedimento descentralizado e o menor número de parlamentares em cada comitê favoreceram a obtenção e a troca de informações, recompensaram os constituintes mais atuantes e propiciaram a elaboração de anteprojetos extensos e detalhistas. As primeiras grandes polêmicas e os contornos básicos da futura Constituição manifestaram-se nessa fase. ${ }^{21}$

As Comissões lograram um projeto, porém ele não foi o texto final votado e aprovado. Em 26 de julho de 1988, o então Presidente José Sarney diria que com o texto até ali existente $o$ país se tornaria ingovernável. Ulisses Guimarães fez um pronunciamento à nação pelas redes de tv em defesa da proposta sistematizada na Comissão de Redação que foi negociada e votada, sendo promulgada em 05 outubro de 1988.

O procedimento foi envolto em tantas polêmicas que o constituinte e ex-ministro do STF Nelson Jobim se tornou centro de uma imensa controvérsia ao dizer, quinze anos depois, que certos artigos da Constituição não haviam sido votados. Posteriormente, melhor se explicando, ele afirmou que a Comissão de Redação inseriu novos textos - que não haviam passado nas Comissões temáticas, o que em tese não deveria ter sido feito. Porém, a Comissão de Redação só realizou acréscimos a partir de votações unânimes. Ademais, Ulisses Guimarães, cuidadoso como foi em todo o processo para evitar qualquer contestação à legitimidade da Constituição Cidadã, fez o texto final ser votado nominalmente e assim todas as decisões tomadas ao longo do processo foram referendadas. $^{22}$

Nas idas e vindas constituintes, o movimento LGBTI+ - à época conhecido como movimento brasileiro de liberação homossexual ${ }^{23}$ - atuou em diversas frentes: a) submeteu emendas por meio especialmente das organizações Triângulo Rosa, Lambda Movimento pela Livre Orientação Sexual e Grupo Gay da Bahia; b) realizou ações de pressão, como o envio de mais de 600 cartas e centenas de ligações para os Constituintes

${ }^{21}$ CPDOC/FGV. Disponível em: http://www.fgv.br/cpdoc/acervo/dicionarios/verbete-tematico/assembleianacional-constituinte-de-1987-88 Acesso em: 22 de junho de 2019.

22 Disponível em: https://www.migalhas.com.br/quentes/187605/historia-dos-artigos-da-constituicao-quenao-foram-votados Acesso em: 17 de junho de 2020

${ }^{23}$ O movimento em sua composição era extremamente diversificado, tendo a presença de homens e mulheres cis e trans. No entanto, naquele período a expressão designada para identificá-lo ainda era incapaz de representar tal pluralidade. Ver: SILVA, Alessandro Soares. Luta, Resistência e Cidadania: uma análise psicopolítica dos movimentos e paradas do orgulho LGBTI+. São Paulo: Juruá, 2009. 166-168. E BACCI, Irina Karla. Vozes Lésbicas no Brasil: a busca e os sentidos da cidadania LGBTI+ (dissertação). 
e c) atuou em advocacy constante nos corredores e marcou a presença em duas Subcomissões. ${ }^{24}$

Na Subcomissão de Direitos e Garantias Individuais da Comissão da Soberania e dos Direitos e Garantias do Homem e da Mulher, realizou-se uma audiência pública com os temas "O homossexual e a Constituição e Instrumentos de participação direta e de iniciativas populares como garantia da cidadania", tendo como palestrantes João Antônio de Souza Mascarenhas e José Geraldo de Souza Júnior.

Na Subcomissão dos Negros, Populações Indígenas, Pessoas Deficientes e Minorias da Comissão da Ordem Social realizou-se a audiência Direitos dos índios / Preservação das reservas indígenas / Sociedades indígenas / Pacto indigenista nacional / Orientação sexual, tendo como expositores Erwin Krauten, Carlos Marés, Vanderlino Teixeira de Carvalho, Manuela Carneiro da Cunha, Mércio Gomes e João Antônio de Souza Mascarenhas.

Nas duas ocasiões, o movimento foi representado por João Antônio Mascarenhas, um dos fundadores do jornal Lampião da Esquina e do grupo carioca Triângulo Rosa. ${ }^{25} \mathrm{Em}$ suas palavras: "a nossa reivindicação é simples, é única. Reivindicamos uma expressa proibição de discriminação por orientação sexual, no dispositivo que deverá substituir o atual art. 153, $\S 1^{\circ 26}$, da Constituição vigente. ${ }^{27} \mathrm{Em}$ uma das ocasiões, após sua fala, o ativista teve de ouvir inúmeras ofensas LGBTI+fóbicas, como as proferidas pelo deputado Ubiratan Spinelli:

principalmente levando outras pessoas a se desencaminharem, principalmente os jovens de 15, 18 e 20 anos, que são levados a mudar a orientação da sua educação exatamente por certos tipos de pessoas que não têm educação; um homossexual de nível mais baixo que são os gays, que são os (sic) travestis, que induzem a juventude ao uso de drogas, e, de

\footnotetext{
${ }^{24}$ Normalmente, as audiências públicas em razão do limite de tempo versaram sobre vários temas diferentes. Verificamos em todas as Comissões e Subcomissões quais as que trataram em audiência pública de questões correlatas aos direitos LGBTI+.

25 HOWES, Robert. João Antônio Mascarenhas (1927-1998): pioneiro do ativismo homossexual no brasil. Disponivel em: https://www.ifch.unicamp.br/ojs/index.php/ael/article/view/2516/1926

26 “Art. 153. A Constituição assegura aos brasileiros e aos estrangeiros residentes no País a inviolabilidade dos

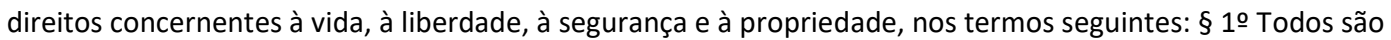
iguais perante a lei, sem distinção de sexo, raça, trabalho, credo religioso e convicções políticas. Será punido pela lei o preconceito de raça." Constituição de 1969. Vale lembrar que, apesar de se afirmar como Emenda Constitucional 01/1969, tratava-se de uma nova Constituição, expressa desde sua própria ementa que dizia: Edita o novo texto da Constituição Federal de 24 de janeiro de 1967.

27 BRASIL. Assembleia Nacional Constituinte. Disponível em: http://imagem.camara.gov.br/Imagem/d/pdf/sup66anc27mai1987.pdf\#page=127 Acesso em: 30 de junho de2020
} 
outros instrumentos e até de dinheiro, para que com eles compartilhem de relações sexuais. ${ }^{28}$ (grifos nossos)

A LGBTI+fobia institucional era a regra, porém alguns parlamentares se mostraram aliados, como Alceni Guerra, Benedita da Silva, Bosco França, Doreto Campanari, Ivo Lechque, José Carlos Sabóia, Nelson Seixas e Osmir Lima Ruy Nedel, que votaram contra retirar a proibição de discriminação por orientação sexual do texto final da Subcomissão dos Negros, Populações Indígenas, Pessoas Deficientes e Minorias da Comissão da Ordem Social. ${ }^{29}$

O termo "orientação sexual" acabou sendo aceito pelas duas Subcomissões, o que representou naquele momento uma grande vitória, porém foi excluído pela Comissão de Redação/Sistematização e posteriormente rejeitado pelo Plenário, em 28 de janeiro de 1988 com 130 votos a favor; 317 votos contra, 14 abstenções e 98 deputados ausentes. ${ }^{30}$

O tema da união estável entre pessoas do mesmo gênero não foi carreado ao debate pelo movimento LGBTI+ e sim por seus opositores. A Constituição de 1988 foi a primeira a tratar da união estável entre duas pessoas. Esta era uma pauta progressista, pois concedia reconhecimento jurídico-constitucional a relações constituídas de fato, evitando a negação de direitos e a discriminação. ${ }^{31}$ Até aquele momento, não existia debate sobre uniões homoafetivas na Constituinte como foi constado em nossa pesquisa.

As Constituições brasileiras já haviam estabelecido o casamento como apenas religioso (1824), apenas civil (1891) e civil, podendo o religioso ter efeitos civis (1934, 1988). ${ }^{32}$ No entanto, nenhuma Constituição brasileira jamais definiu o casamento como apenas entre homem e mulher, nem a de 1988. O Código Civil de 1916, vigente por 86 anos, também não. Está patente aí a "demanda suprimida": não existiam projetos de

28 BRASIL. Assembleia Nacional Constituinte. Disponível http://imagem.camara.gov.br/Imagem/d/pdf/sup115anc05ago1987.pdf\#page=87 Acesso em: 30 de junho de 2020.

29 VILALON, Eduardo Martins de Azevedo. O Movimento Homossexual Brasileiro na Constituinte De 87-88: Apontamentos Iniciais sobre As Discussões Na Subcomissão Dos Negros, Populações Indígenas, Pessoas Deficientes e Minorias Disponível em: https://anaiscongressodivsex.files.wordpress.com/2015/03/49eduardo-vilalon.pdf Acesso em: 07 de julho de 2019.

30 HOWES, Robert. João Antônio Mascarenhas (1927-1998): pioneiro do ativismo homossexual no brasil. Disponível em: https://www.ifch.unicamp.br/ojs/index.php/ael/article/view/2516/1926 Acesso em: 01 de julho de 2019.

31 MENEZES, Joyceane Bezerra de. A dimensão constitucional da união estável - e o direito sucessório?. Nomos (Fortaleza), v. 25, p. 113-128, 2006.

32 COSTA, Dilvanir José da. A família nas Constituições Brasília a. 43 n. 169 jan./mar. 2006 Disponível em: http://www2.senado.leg.br/bdsf/bitstream/handle/id/92305/Costa\%20Dilvanir.pdf?sequence=6\&isAllowed =y Acesso em 15 de junho de 2020 . 
textos normativos estabelecendo o direito e por muito tempo sequer o Sistema de Justiça foi tensionado a reconhecer tais uniões. Não estava sequer expressa uma proibição. E não podemos dizer que a demanda social era inexistente. Relações estáveis e duradouras entre pessoas LGBTI+s existiam ${ }^{33}$, mas essa existência não se transformava em uma demanda por uma norma jurídica.

A ausência da determinação de que o casamento teria de se dar entre homem e mulher não impediu que todos os manuais de direito civil e decisões judiciais insistissem por décadas na inexistência jurídica de relações LGBTI+. ${ }^{34}$ Apenas quando o tema passou a ser socialmente vocalizado houve a preocupação do Constituinte definir a união estável entre homem e mulher e dos redatores do Código Civil de 2003 expressarem que " 0 casamento se realiza no momento em que o homem e a mulher manifestam, perante $o$ juiz, a sua vontade de estabelecer vínculo conjugal, e o juiz os declara casados"(art. $1514)^{35}$.

Por certo, era um pressuposto durante longos anos que apenas a união entre homem e mulher poderia ser considerada casamento. Após extensivo estudo sobre decisões judiciais acerca do tema, Adilson Moreira diz que: "inúmeros juízes achavam que a ideia da união estável homossexual ou o casamento civil homossexual era uma contradição em termos, visto que a diversidades dos sexos é parte fundamental destas instituições"36. A permanência da ideia da heterossexualidade como natural tem função primordial na manutenção da ordenação social tradicional e patriarcal.

“A heterossexualidade não pode ser entendida apenas como uma orientação sexual. Ela legitima uma série de arranjos sociais que sustentam relações assimétricas de poder. ${ }^{\prime \prime 37}$ A demanda por reconhecimento das relações LGBTI+ contraria um conjunto de entendimentos socioculturais enraizados. Se na lei civil brasileira, a mulher casada possuía

\footnotetext{
33 LIFSHITZ, Sebastien. The Invisibles: Vintage Portraits of Love and Pride. Gay Couples in the Early Twentieth Century. New York: Rizzoli , 2014, 144p. E TREVISAN, João Silvério. Devassos no Paraíso. São Paulo: Objetiva, 2018, p 155-220.

${ }^{34}$ VECHIATTI, Paulo Robert lotti. Manual da Homoafetividade; São Paulo: Metódo, 2013, p. 158-161.

35 Texto mantido desde a proposta original, PL 634/1975. https://www.camara.leg.br/proposicoesWeb/fichadetramitacao?idProposicao=15675 Acesso em: $16 \mathrm{de}$ junho de 2020.

36 MOREIRA, A. J. Cidadania Sexual: Estratégia para Ações Inclusivas. 1. ed. São Paulo: Arraes Editores, 2017. v. 1, p. 88.

37 MOREIRA, A. J. Cidadania Sexual: Estratégia para Ações Inclusivas. 1. ed. São Paulo: Arraes Editores, 2017. v. 1, p. 91.
} 
até 1988 limitações ao exercício de seus direitos ${ }^{38}$, o que se diria de uma mulher que não só pretendesse ter autonomia quanto decidisse que sua família seria formada por duas mulheres?

Apenas em 2008, a turma especial do STJ reconheceu pela primeira vez a Vara de Família como competente para tratar de uniões estáveis LGBTI+, reformando decisão do Tribunal de Justiça do Rio que considerava ser caso de competência da vara cível. ${ }^{39}$

Desta forma, em 1988, quando se depararam com a proposta de reconhecimento da união estável, os Constituintes se insurgiram contra qualquer possibilidade de reconhecimento das uniões homoafetivas. Na Comissão de Redação, o constituinte Gastone Righi argumentou:

Finalmente a emenda do Constituinte Roberto Augusto. É o Artigo 225, § 3ㅇ Este parágrafo prevê: "Para efeito da proteção do Estado, é reconhecida a união estável entre homem e mulher como entidade familiar, devendo a lei facilitar sua conversão em casamento." Tem-se prestado a amplos comentários jocosos, seja pela imprensa, seja pela televisão, com manifestação inclusive de grupos gays através do País, porque com a ausência do artigo poder-se-ia estar entendendo que a união poderia ser feita, inclusive, entre pessoas do mesmo sexo. Isto foi divulgado, por noticiário de televisão, no show do Fantástico, nas revistas e jornais. 0 bispo Roberto Augusto, autor deste parágrafo, teve a preocupação de deixar bem definido, e pede que se coloque no $\S$ 3o dois artigos: "Para efeito da proteção do Estado, é reconhecida a união estável entre o homem e a mulher, como entidade familiar, devendo a lei facilitar sua conversão em casamento". Claro que nunca foi outro o desiderato desta Assembleia, mas, para se evitar toda e qualquer malévola interpretação deste austero texto constitucional, recomendo a V. Ex. a que me permitam aprovar pelo menos uma emenda. ${ }^{40}$ (grifos nossos)

Veja-se, portanto que a demanda pelo reconhecimento das uniões já existia e foi pautada na mídia. Porém, juridicamente, era uma demanda suprimida, pois não havia sido levada pelos movimentos sociais aos Constituintes. O pronunciamento destes se deu em negação a qualquer possibilidade de inclusão. Isso faz com que até hoje parlamentares conservadores aleguem que a vontade do Constituinte deveria ser preservada e que o

\footnotetext{
38 Lembremos que o Estatuto da Mulher Casada retirava algumas limitações de direitos existentes no Código Civil, mas ainda não instituía a igualdade entre homens e mulheres. BRASIL. Lei 4121/1962. Disponível em: http://www.planalto.gov.br/CCIVIL_03/LEIS/1950-1969/L4121.htm Acesso em: 15 de junho de 2020.

39 AMARAL, Sylvia Maria Mendonça. União homossexual como Direito de Família. Disponível: https://migalhas.uol.com.br/depeso/70205/uniao-homossexual-como-direito-de-familia Acesso em 13 de novembro de 2020.

40 Disponível em: https://www.senado.leg.br/publicacoes/anais/constituinte/redacao.pdf Acesso em: 30 de junho de 2019.
} 
Supremo Tribunal Federal e o Conselho Nacional de Justiça se excederam ao reconhecerem tais direitos. ${ }^{41}$

Mais uma vez destacamos que quando defendemos uma perspectiva de direitos fundamentais como conquistas sociais estamos justamente demonstrando que as tensões sociais em torno deles, especialmente daqueles que provocam profundas mudanças socioculturais, são persistentes. Portanto, são um conjunto de embates políticos, jurídicos, culturais que vão planificando o terreno para que direitos antes considerados inexistentes sejam obtidos.

2. Como os 16 anos de luta no parlamento foram decisivos para marinar a vitória pela via judicial.

As derrotas do movimento LGBTI+ na Constituinte já eram esperadas. O preconceito e a discriminação legitimavam-se - e legitimam-se até hoje - no conservadorismo e em valores religiosos atrelados a um Estado pouco laico na prática. ${ }^{42}$ No entanto, de tais derrotas vieram aprendizados importantes, como a necessidade de valorização do diálogo e a formação de estratégias com parlamentares parceiros e negociações com opositores sensíveis a partir de argumentos capazes de convencê-los da importância do reconhecimento jurídico destes relacionamentos.

Há argumentos de que o movimento LGBTI+ se tornou muito conservador por focar tanto numa pauta como o casamento ao invés de privilegiar um debate mais ousado sobre existências e direitos. ${ }^{43}$ Acreditamos, no entanto, que há uma razão justificadora desta posição. Em sociedades patriarcais, como a brasileira, fundadas na ampla valorização de um ideal de família, quando se alega que determinadas uniões de afeto não podem ser consideradas família, está-se automaticamente legitimando toda uma

\footnotetext{
${ }^{41}$ BRASIL. Parecer da Relatora na Comissão de Constituição, Justiça e Cidadania (CCJC) ao PL 4754/2016, p. $05 . \quad$ Disponível em: https://www.camara.leg.br/proposicoesWeb/prop_mostrarintegra?codteor=1769130\&filename=PRL+3+CCJ C+\%3D\%3E+PL+4754/2016 Acesso em 12 de junho de 2020 42

MISKOLCl, Richard. Pânicos morais e controle social: reflexões sobre o casamento gay. Cad. Pagu [online] 2007, n.28, pp.101-128. ISSN 1809-4449. https://doi.org/10.1590/S0104-83332007000100006.

43 WARNER, Michael. The Trouble with Normal: Sex, Politics, and the Ethics of Queer Life. Boston: Harvard University Press/New Ed edition, 1999, 227p.
} 
sorte de preconceitos. Como bem sintetizou Audre Lorde, "a menos que alguém viva e ame dentro das trincheiras, é difícil se lembrar que a guerra contra a desumanização é interminável"144.

Em 1995, a então deputada federal Marta Suplicy, a partir de amplo diálogo com os movimentos sociais, apresentou o primeiro projeto de lei de "união civil entre pessoas do mesmo sexo", voltado a regular especialmente os direitos de propriedade e sucessão, como consta em sua justificativa:

\begin{abstract}
A possibilidade de regularizar uma situação de união já existente tornará estes relacionamentos mais estáveis, na medida que serão solucionados problemas práticos, legais e financeiros. A vida social dos casais homossexuais também será afetada, fazendo com que sejam melhor aceitos pelas sociedade e até pelas próprias famílias. (..) Esse projeto procura disciplinar a união civil entre pessoas do mesmo sexo e não se propõe a dar às parcerias homossexuais um status igual ao casamento. $O$ casamento tem um status único. Este projeto fala de "parceria" e "união civil". Os termos "matrimônio" e "casamento" são reservados para o casamento heterossexual com suas implicações ideológicas e religiosas. ${ }^{45}$
\end{abstract}

O projeto tramitou por 12 anos, gerando amplos embates e foi aprovado em dezembro de 1996 na Comissão Especial com Substitutivo do então deputado federal Roberto Jeferson que, dentre outras mudanças, trocava a designação de união civil para parceria civil. A última tentativa de levá-lo a plenário se deu em 2007. Mas isso de fato nunca ocorreu, nem ele tampouco foi arquivado. Ele continua tramitando e, ao longo dos anos, foram sendo juntados novos projetos, alguns para avançar em direitos e outros para retroceder.

A realidade, no entanto, não depende da existência da norma jurídica. Muitos casais foram ao longo deste tempo precisando de respostas jurídicas às suas legitimas demandas e para isso buscaram o amparo do Sistema de Justiça.

Porém, durante a década de 1990, tanto o debate parlamentar quanto o jurisprudencial sobre as uniões LGBTI+ destinavam-se a reconhecer o efeito patrimonial das uniões, como se um contrato cível qualquer houvera sido desenvolvido durante o período em que aquele casal partilhou uma vida conjunta. ${ }^{46}$

O entendimento inicial era da ausência de direitos. Aos poucos, o argumento de que seria injusto se desconsiderar as relações patrimoniais entre as duas partes passou a

44 LORDE, Audre. Irmã Outsider. São Paulo: autêntica, 2019, p. 147.

45 BRASIL. Projeto de Lei 1151/1995. Disponível em: http://imagem.camara.gov.br/Imagem/d/pdf/DCD21NOV1995.pdf\#page=41 Acesso em 02 de julho 2019. ${ }^{46}$ Recurso Especial no 154.857 - 6a Turma, Relator Ministro Vicente Cernicchiaro, DJ 26.10.1998). 
convencer parte da jurisprudência. Admitia-se a existência um contrato cível, mas não uma relação familiar de afeto. ${ }^{47}$

Pedidos de pensão ao INSS e direitos de herança foram sendo levados ao Sistema de Justiça. O 4으 Grupo Cível do Tribunal de Justiça do Rio Grande do Sul reconheceu pela primeira vez o direito sucessório de companheiro homossexual em $2003 .{ }^{48} \mathrm{O}$ primeiro pronunciamento do Supremo Tribunal Federal também foi neste ano e veio do Ministro Marco Aurélio, que negou pedido do INSS para suspender pensão ganha por companheiro homossexual concedida pelo Tribunal Regional da 4a Região. ${ }^{49}$

O entendimento de muitos juristas era de que, resolvida essa questão patrimonial, não havia necessidade de se exigir nada mais. Condenavam assim as relações a só serem legitimadas quando terminavam e apenas para resolução de questões financeiras. ${ }^{50}$

A literatura jurídica foi pioneira em discordar do mero caráter patrimonial destas relações. Roger Raupp Rios ${ }^{51}$ e Maria Berenice Dias $^{52}$ já alertavam não se tratarem estas uniões de meros contratos. Maria Berenice Dias é reconhecida por sua defesa do afeto como digno de tutela jurídica e jurisdicional, sendo ela autora da expressão homoafetividade.

Aliadas a este texto mais específico estava toda a construção dos constitucionalistas em torno do postulado da dignidade da pessoa humana, que ajudou a moldar um sentimento constitucional voltado a uma interpretação sistemática que tem como norte concretizá-lo. ${ }^{53}$

Além do que, a Organização Mundial de Saúde (OMS) retirou em 1990 a homossexualidade do rol de distúrbios e o debate sobre união estável e casamento

47 MOREIRA, A. J. Cidadania Sexual: Estratégia para Ações Inclusivas. 1. ed. São Paulo: Arraes Editores, 2017. v. 1 , pp. 81-89.

48 CONSULTOR JURÍDICO. Justiça gaúcha reconhece união estável entre homossexuais Disponível em: https://www.conjur.com.br/2003-mai-12/tj_gaucho_reconhece_uniao_estavel_entre_homossexuais Acesso em: 17 de junho de 2020

49 STF. Petição 1984-9. Disponível em: http://www.stf.jus.br/portal/cms/verNoticiaDetalhe.asp?idConteudo=60059 Acesso em: 17 de junho de 2020

50 VECHIATTI, Paulo Robert lotti. Manual da Homoafetividade; São Paulo: Metódo, 2013, p. 163-185.

${ }^{51}$ RIOS, R. R. A justiça e os direitos de gays e lésbicas - jurisprudência comentada. Porto Alegre: Sulina, 2003.

52 DIAS, Maria Berenice. Homoafetividade: o que diz a Justiça! Porto Alegre: Livraria do Advogado, 2003.

53 SARLET, I. W. Dignidade da Pessoa Humana e Direitos Fundamentais na Constituição Federal de 1988. 1. ed. Porto Alegre: Livraria do Advogado, 2001. v. 1. 152p .

SARMENTO, Daniel. Livres e Iguais: Estudos de Direito Constitucional. Rio de Janeiro: Lumen Juris, 2006. 308p 
LGBTI+ esteve em pauta em inúmeros países, sendo capitaneado pelos atores políticos (movimentos sociais e ativistas) a partir de estratégias adequadas aos seus próprios contextos. A existência do tema no debate público é também um importante modo de se construit uma mudança de mentalidade capaz de influenciar os atores políticos estatais. ${ }^{54}$ Afinal, parlamentares e ministros de Tribunais Superiores são agentes do Estado, mas não são autores neutros. O Ministro Luís Roberto Barroso reconhece isto quando afirma:

O Direito pode e deve ter uma vigorosa pretensão de autonomia em relação à política. Isso é essencial para a subsistência do conceito de Estado de direito e para a confiança da sociedade nas instituições judiciais. A realidade, contudo, revela que essa autonomia será sempre relativa. Existem razões institucionais, funcionais e humanas para que seja assim. Decisões judiciais, com frequência, refletirão fatores extrajurídicos. Por longo tempo, a teoria do Direito procurou negar esse fato, a despeito das muitas evidências. Pois bem: a energia despendida na construção de um muro de separação entre o Direito e a política deve voltar-se agora para outra empreitada. Cuida-se de entender melhor os mecanismos dessa relação intensa e inevitável, com o propósito relevante de preservar, no que é essencial, a especificidade e, sobretudo, a integridade do Direito. ${ }^{55}$

Interessante lembrar que, entre 1975 e 2002, tramitou no Congresso Nacional a proposta de um novo Código Civil, o qual foi amplamente debatido no Senado na década de 1990 e na Câmara no início dos anos 2000. O texto não prevê qualquer possibilidade de regular as uniões LGBTI+ e definiu o casamento e a união estável como entre homem e mulher. Algo, como já salientado, inexistente na norma mais antiga.

Ainda assim, surgiram propostas avançadas no meio do caminho, como a Proposta de Emenda Constitucional 70/2003 do Senador Sérgio Cabral, com o intuito de propor a alteração do §3 do artigo 226 da Constituição: "para efeito da proteção do estado, é reconhecida a união estável entre casais heterossexuais ou homossexuais, como entidade familiar, devendo a lei facilitar sua conversão em casamento quando existente entre homem e mulher" ${ }^{56}$ A proposta foi retirada pelo próprio autor em 2006, porém é de sua autoria a ADPF 132, que julgada junto com ação direta de inconstitucionalidade

54 FOLHA DE SÃO PAULO. https://www1.folha.uol.com.br/fsp/mundo/ft1907200106.htm ; https://www1.folha.uol.com.br/fsp/mundo/ft1601200214.htm; https://www1.folha.uol.com.br/fsp/mundo/ft1606200311.htm Acesso em 17 de junho de 2020

55 BARROSO, Luís Roberto. Contramajoritário, Representativo e lluminista: Os papeis dos tribunais constitucionais nas democracias contemporâneas / Countermajoritarian, Representative, and Enlightened: The roles of constitutional tribunals in contemporary democracies. Revista Direito e Práxis, [S.I.], v. 9, n. 4, p. 2171-2228, dez. 2018. ISSN 2179-8966. Disponível em: <https://www.epublicacoes.uerj.br/index.php/revistaceaju/article/view/30806/21752>. Acesso em: 17 jun. 2020.

56 SENADO FEDERAL. PEC 70/2003. Disponível em: https://www25.senado.leg.br/web/atividade/materias//materia/61093 Acesso em: 16 de junho de 2020. 
4277 proposta pela Procuradoria Geral da República, findou por obter o aval do STF a tais uniões.

Em 2007, Clodovil Hernandes (PTC/SP), primeiro parlamentar assumidamente gay, eleito por um partido cristão conservador, propôs o PL 580/2007, para alterar o Código Civil para dispor que: Art. 839-A. Duas pessoas do mesmo sexo poderão constituir união homoafetiva por meio de contrato em que disponham sobre suas relações patrimoniais.

Interessante notar que o único parlamentar assumidamente homossexual tinha, para o período, uma postura recuada, pois o Tribunal de Justiça do Rio Grande do Sul reconheceu pela primeira vez o status familiar de uma relação LGBTI+ quatro anos antes. 57

Entre 1995 e 2007, os movimentos sociais LGBTI+ foram presença constante nos corredores do Congresso Nacional, participando de audiências públicas dialogando com parlamentares aliados e empreendendo negociações com opositores. ${ }^{58}$. Estão disponíveis no site da Câmara requerimentos de audiências públicas, entre 2005 e 2019, constando como convidadas a Associação Brasileira de Gays, Lésbicas, Travestis e Transexuais em 27 ocasiões, a Associação de Lésbicas Brasileiras em 21 e a Associação Nacional de Travestis e Transexuais em 09. Além disso, desde 2004, realizam-se Seminários LGBTI+ anualmente, numa parceria entre mandatos aliados e os movimentos sociais para discussão e visibilização de temas de importância para a comunidade LGBTI+. ${ }^{59}$

Ao mesmo tempo em que participavam de debates no parlamento, os ativistas e organizações de defesa dos direitos LGBTI+s passaram a buscar apoio no Sistema de Justiça. Em dezembro de 2006, o Grupo de Trabalho de Direitos Sexuais e Reprodutivos da Procuradoria Federal dos Direitos do Cidadão do Ministério Público Federal entregou estudo ao Procurador Geral da República demandando:

ajuizamento de Arguição de Descumprimento de Preceito Fundamental para que o STF profira decisão dotada de eficácia erga omnes e efeito vinculante, para: a) declarar a obrigatoriedade do reconhecimento, como entidade

57 CONSULTOR JURÍDICO. JULGAMENTO POLÊMICO Justiça gaúcha reconhece união estável entre homossexuais. Disponivel em: https://www.conjur.com.br/2003-mai12/tj_gaucho_reconhece_uniao_estavel_entre_homossexuais Acesso em 15 de junho de 2020

58 Disponível em: https://www2.camara.leg.br/camaranoticias/noticias/DIREITOS-HUMANOS/147752RELIGIOSOS,-JURISTAS-E-ONGS-DIVERGEM-SOBRE-UNIAO-CIVIL-GAY.html Acesso em: 12de junho 2020 https://www2.camara.leg.br/camaranoticias/noticias/DIREITOS-HUMANOS/147941-HOMOSSEXUAISCRITICAM-LENTIDAO-DO-CONGRESSO-PARA-APROVAR-SEUS-DIREITOS.htmI Acesso em: 15 de junho de 2020. 59 Disponivel em: https://www2.camara.leg.br/atividade-legislativa/comissoes/comissoespermanentes/cdhm/documentos/relatorios-de-atividades. Acesso em: 15 de junho de 2020. 
familiar, da união entre pessoas do mesmo sexo, desde que atendidos os mesmos requisitos exigidos para a constituição da união estável entre homem e mulher; e b) declarar que os mesmos direitos e deveres dos companheiros nas uniões estáveis estendam-se aos companheiros nas uniões entre pessoas do mesmo sexo. ${ }^{60}$

O documento serviu de base para a ação que seria proposta em julho de 2009, quando a Subprocuradora da República Debora Duprat assumiu interinamente o cargo de Procuradora Geral da República, e julgada pelo STF em 2011 reconhecendo a união LGBTI+.

Ainda em 2007, o deputado Sergio Barradas redigiu em parceria com o Instituto Brasileiro de Direito de Família (IBDFAM) o PL 2285/2007 para criar um Estatuto das Famílias, o qual em seu artigo 68 preconizava:

Art. 68. É reconhecida como entidade familiar a união entre duas pessoas de mesmo sexo, que mantenham convivência pública, contínua, duradoura, com objetivo de constituição de família, aplicando-se, no que couber, as regras concernentes à união estável. Parágrafo único. Dentre os direitos assegurados, incluem-se: I - guarda e convivência com os filhos; II - a adoção de filhos; III - direito previdenciário; IV - direito à herança. ${ }^{61}$

A sacralidade do casamento num Estado pretensamente laico não deveria ser sequer cogitada. No entanto, esse ideal permeou decisões judiciais e era argumento utilizado para a rejeição ao reconhecimento das uniões estáveis LGBTI+s, pois estas poderiam levar ao direito ao casamento. Tentando assegurar ao menos alguns direitos para a população LGBTI+, os movimentos e parlamentares de diversos espectros ideológicos negociarem um texto garantindo às relações $L G B T I+$ o mesmo regime dado às uniões estáveis heteroafetivas, excetuando-se apenas a possibilidade de casamento. ${ }^{62}$

No mesmo ano, foi apensado outro projeto, este do deputado Capitão Assunção, proibindo a equiparação de qualquer relação entre pessoas do mesmo sexo a casamento ou entidade familiar, pois, segundo ele, "formalizar na lei brasileira a união entre pessoas do mesmo sexo contribui para a desagregação familiar".

\footnotetext{
60 Disponível em: http://pfdc.pgr.mpf.mp.br/informativos/edicoes-2006/dezembro/representacao-ao-pgrsobre-uniao-entre-pessoas-do-mesmo-sexo/ Acesso em: 12de junho 2020 61

https://www.camara.leg.br/proposicoesWeb/prop_mostrarintegra?codteor=517043\&filename=PL+2285/20 07

62 PL 4914/2009, por José Genoíno (PT), Manuela D'ávila (PCdoB), Maria Helena (PSB), Celso Russomanno (PP), Ivan Valente (PSOL) Fernando Gabeira (PV), Arnaldo Faria de Sá (PTB), Solange Amaral (DEM), Marina Maggessi (PPS), Colbert Martins (PMDB), Paulo Rubem Santiago (PDT) e Professora Raquel Teixeira (PSDB). Disponível em: https://www.camara.leg.br/proposicoesWeb/fichadetramitacao?idProposicao $=427692$ Acesso em: 14 de junho de 2020
} 
É pertinente lembrar que em 2009 foi promulgado, pelo Decreto 7037/2009, do Presidente Lula, o Programa Nacional de Direito Humanos III (PNDH-3), criado na 14a Conferência Nacional de Direitos fundamentais, fruto de uma parceria entre o Executivo Federal e a Comissão de Direitos fundamentais e Minorias da Câmara dos Deputados, e que contou, se analisadas também as etapas municipais e estaduais, com a participação de mais de 14 mil pessoas. ${ }^{63}$

O PNDH-3 não detinha a capacidade jurídica de criar nenhum direito, apenas demonstrava a interlocução entre aqueles atores políticos e estabelecia diretrizes, objetivos estratégicos e ações programáticas. Tratava-se de uma carta de intenções negociada entre o Poder Público e os movimentos sociais de direitos fundamentais. No entanto, se tornou alvo de uma imensa polêmica por trazer ínsitas diretrizes como: aborto como uma questão de saúde pública; democratização da mídia; necessidade de instauração de uma Comissão Nacional da Verdade para rever os crimes da ditadura civilmilitar; e a união estável e o direito de adotar de pessoas LGBTI+.

Ainda que nenhum direito tenha sido criado, o PNDH-3 foi uma vitória dos movimentos de direitos fundamentais em conseguir do governo um compromisso com pautas históricas. Isto gerou um coro de descontentes entre parlamentares e figuras públicas religiosas conservadoras que hoje nominamos necrocristãs ${ }^{64}$, ou seja, atores políticos que usam a pauta cristã para tensionar com a laicidade, negar direitos a mulheres, LGBTI+, indígenas e quilombolas, dentre outros grupos socialmente minorizados. ${ }^{65}$ Após os protestos, foi lançado novo decreto com uma versão suavizada do programa, mas que mantinha as diretrizes em prol de LGBTI+s. ${ }^{66}$

Como se vê, ao longo dos anos, foram inúmeras as tentativas de se obter o reconhecimento do direito de duas pessoas adultas constituírem suas famílias do modo que Ihes apraz. 32 anos depois da Constituinte ainda não há lei federal sobre o tema.

A estratégia de atuar em duas frentes - a legislativa e a jurisdicional - gerou frutos ao movimento LGBTI+. Quando o tema chegou ao Supremo, já existiam décadas de

63 BRASIL. Decreto 7037/2010. Disponível em: http://www.planalto.gov.br/ccivil_03/_ato20072010/2009/decreto/d7037.htm Acesso em: 14 de junho de 2020.

64 Disponível em: https://www1.folha.uol.com.br/poder/812271-bancada-evangelica-quer-barrar-o-planode-direitos-humanos.shtml Acesso em: 14 de junho de 2020.

65 O termo necrocristão deriva de uma interpretação da chave teórica "necropolitica" desenvolvida por Achille Mbembe para interpretar a pulsão de morte social transformada em política de morte. Ver mais: https://revistas.ufrj.br/index.php/ae/article/view/8993/7169]+

66 BRASIL. Decreto 7177/2010 http://www.planalto.gov.br/ccivil_03/_ato20072010/2010/Decreto/D7177.htm\#art1 Acesso em: 14 de junho de 2020 
debate no Legislativo, decisões proferidas por diversos juízes e Tribunais e inclusive pronunciamentos monocráticos provenientes de Ministros do STJ e STF.

As ações da PGR (ADI 4277) e do Governo do Estado do Rio de Janeiro (ADPF 132) foram apensadas e julgadas conjuntamente. Participaram como amicus curae treze entidades favoráveis ao pleito e duas contrárias ${ }^{67}$. Nenhuma entidade de designação evangélica pediu para participar como amigo da corte. No entanto, no ano seguinte era fundada a Associação Nacional de Juristas Evangélicos (ANAJURE), entidade que hoje atua na redação de projetos de lei e pareceres e está presente em diversos julgamentos de interesse da comunidade LGBTI+ no Supremo, sempre manifestando-se contrariamente. ${ }^{68}$

O acórdão decidido de forma unânime pelos dez ministros votantes reconhece a proibição da discriminação, "a liberdade para dispor da própria sexualidade, inserida na categoria dos direitos fundamentais do indivíduo, expressão que é da autonomia de vontade" e procede a um "tratamento constitucional da instituição da família", reconhecendo "que a constituição federal não empresta ao substantivo "família" nenhum significado ortodoxo ou da própria técnica jurídica". ${ }^{69}$

No mesmo ano, o Superior Tribunal de Justiça (STJ) julgou procedente o Recurso Especial 1.183.378/RS, autorizando Katia Ozório e Leticia Perez a procederem habilitação para se casarem. Na histórica decisão, a 4a Turma do STJ se referiu ao acórdão de reconhecimento da união estável pelo STF e dentre outros argumentos, reconheceu que:

A igualdade e o tratamento isonômico supõem o direito a ser diferente, 0 direito à autoafirmação e a um projeto de vida independente de tradições e ortodoxias. Em uma palavra: o direito à igualdade somente se realiza com plenitude se é garantido o direito à diferença. Conclusão diversa também não se mostra consentânea com um ordenamento constitucional que prevê o princípio do livre planejamento familiar (§ 70 do art. 226). E é importante ressaltar, nesse ponto, que o planejamento familiar se faz presente tão logo haja a decisão de duas pessoas em se unir, com escopo de constituir família, e desde esse momento a Constituição Ihes franqueia ampla liberdade de escolha pela forma em que se dará a união. ${ }^{70}$

Apesar de tratar-se de um caso concreto, o processo foi uma expressão de litigância estratégica, pois elas tinham um relacionamento consistente e uma atuação

\footnotetext{
67 BRASIL Supremo Tribunal Dederal. Disponível https://jurisprudencia.stf.jus.br/pages/search/sjur200017/false Acesso em: 14 de junho de 2020 ${ }^{68}$ ADI 5537 (Escola sem Partido), ADO 26 e MI 4733 (Criminalização da LGBTI+fobia).

69 BRASIL. Supremo Tribunal Federal. Acórdão na integra: http://redir.stf.jus.br/paginadorpub/paginador.jsp?docTP=AC\&doclD=628633 Acesso em 09 de julho de 2019.

70 Idem nota 09.
} 
ativista. Foram patrocinadas por advogados de uma organização não governamental tradicional da defesa dos direitos LGBTI+ no Rio Grande do Sul, a "Somos", numa estratégia judicial iniciada na primeira instância em 2009 e que as levou até o STJ em 2011, poucos meses após a decisão do STF.

Tanto a decisão do STF quanto a do STJ foram, portanto, tomadas em um contexto de décadas de luta do movimento LGBTI+, que se utilizou de posições estratégicas, aliados institucionais e atuou de modo eficaz para buscar na via judicial direitos que vinham sendo obstados pela via do legislativo.

A decisão do STF obteve resistência nas instâncias inferiores do Judiciário. ${ }^{71} \mathrm{O}$ Conselho Nacional de Justiça (CNJ), considerando ambas as decisões, emitiu a Resolução $175 / 13$.

Parlamentares contrários ao reconhecimento de direito LGBTI+ também se insurgiram contrariamente. Foram propostos Projetos de Decreto Legislativo ${ }^{72}$ pelos deputados João Campos e Marco Feliciano ${ }^{73}$ com o intuito de sustar as decisões do Supremo Tribunal Federal que reconheciam a união estável LGBTI+. Ambas as propostas foram devolvidas aos autores por serem evidentemente inconstitucionais (art. 137, § 1으, inciso II, alínea "b", do Regimento Interno da Câmara dos Deputados).

Os decretos legislativos têm dentre suas funções sustar os atos normativos do Poder Executivo que exorbitem do poder regulamentar ou dos limites de delegação legislativa (art. 49, V, Constituição Federal). Não se prevê, portanto, a sustação de atos mesmo aqueles com poder normativo - provenientes do Judiciário.

Marco Feliciano, em uma outra tentativa, propôs a realização de um plebiscito sobre o reconhecimento legal da união homossexual como entidade familiar. Sua alegação mais uma vez era a de que o STF exorbitou de seus poderes e por isso a população precisaria ser consultada. $\mathrm{O}$ deputado André Zacharow fez proposta similar. 0

71 Disponível em: http://m.g1.globo.com/brasil/noticia/2011/06/juiz-de-goias-que-anulou-uniao-de-casalgay-nega-ser-homofobico.html;https://noticias.uol.com.br/cotidiano/ultimas-noticias/2012/07/06/juizacontraria-determinacao-do-stf-e-nega-pedido-de-casamento-homoafetivo-em-

goiania.amp.htm;https://www.otempo.com.br/mobile/cidades/gays-enfrentam-dificuldades-para-se-casarem-cart\%C3\%B3rios-de-belo-horizonte-1.644926?amp;

https://www.brasildefato.com.br/2018/06/21/promotor-tenta-anular-casamentos-homoafetivos-emflorianopolis/ Acesso em: 07 de julho de 2019.

72 Note--se que até 2019 a Câmara usava a sigla PDC para designar os Projetos de Decreto Legislativo e o Senado utiliza PDL. A partir de 2019, a sigla foi uniformizada para PDL.

73 BRASIL. Câmara dos Deputados. PDC 637/2012 Disponível em: https://www.camara.leg.br/proposicoesWeb/fichadetramitacao?idProposicao $=552023$ Acesso em: $120 / 6 / 2020$ 
instrumento jurídico cabível neste caso é um projeto de decreto legislativo com assinatura de pelo menos $1 / 3$ dos parlamentares (art. 3 o da Lei 9079/1998). Como ambas as propostas foram aceitas para tramitação, entendemos que houve o apoiamento de pelo menos $1 / 3$.

Foram apresentados ainda quatro projetos de decreto legislativo com o objetivo de sustar a Resolução 175/2013 do Conselho Nacional de Justiça pelos deputados Marcos Rogério, ${ }^{74}$ Arolde de Oliveira ${ }^{75}$ e Prof. Victório Galli ${ }^{76}$ e pelo senador Magno Malta ${ }^{77}$. Nenhum dos projetos foi aprovado.

Já Estatuto da Família, PL 6583/2013, foi aprovado por Comissão Especial da Câmara e encontra-se pronto para ir ao Senado desde 08 de outubro de 2015. O projeto, do deputado Anderson Ferreira (PR), estabelece como "entidade familiar como o núcleo social formado a partir da união entre um homem e uma mulher, por meio de casamento ou união estável, ou ainda por comunidade formada por qualquer dos pais e seus descendentes". Pende, no entanto, um recurso ao Presidente da Câmara dos Deputados contra o fato de que em seu despacho inicial o projeto foi indicado como terminativo nas Comissões, ou seja, sua aprovação não dependeria de votação no Plenário. O recurso pretende reverter tal determinação.

O texto do projeto e sua justificativa não tocam nas decisões em benefícios dos casais LGBTI+, entretanto, os debates e audiências públicas conduzidos, assim como os dois pareceres favoráveis ao projeto - dos deputados Ronaldo Fonseca e Diego Garcia expressam como motivação as decisões em favor dos casais LGBTI+. ${ }^{78}$ Representativa de toda esta estratégia foi a audiência pública realizada entre o Pastor Silas Malafaia e o ativista Toni Reis, à época presidente da $\mathrm{ABGLT},{ }^{79}$ na qual Silas Malafaia professa:

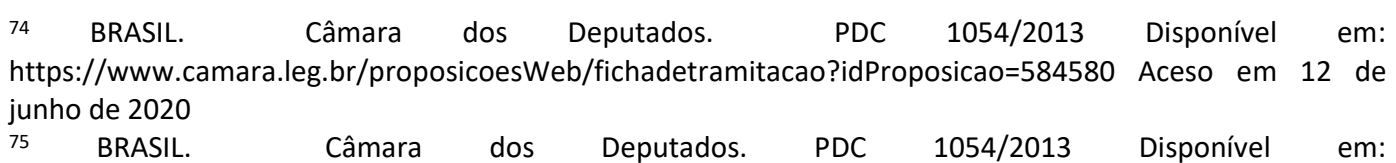
75 BRASIL. Câmara dos Deputados. PDC 1054/2013 Disponível em:
https://www.camara.leg.br/proposicoesWeb/fichadetramitacao?idProposicao=578114\&ord=1 Acesso em: 12 de junho de 2020

76 BRASIL. Câmara dos Deputados. PDC 639/2017 Disponível: https://www.camara.leg.br/proposicoesWeb/fichadetramitacao?idProposicao=2132541 Acesso em: 12 de junho de 2020

77 BRASIL. PDL 106/2013. Disponível: https://www25.senado.leg.br/web/atividade/materias//materia/112745 Acesso em: 12 de junho de 2020.

78 BRASIL. Câmara dos Deputados. Disponível em: https://www.camara.leg.br/proposicoesWeb/prop_pareceres_substitutivos_votos?idProposicao=597005 Acesso em: 14.06.2020.

79 BRASIL. Câmara dos Deputados. Disponível em: https://escriba.camara.leg.br/escribaservicosweb/html/39619 Acesso em 15.06.2020 
Inicialmente acho muito importante essa discussão. Concordo plenamente que o Congresso Nacional tem que tomar as decisões. Se ele não tomar a decisão, o STF vai tomá-la. É muito importante que se vote aqui.

0 que aconteceu? Eu estive aqui neste mesmo local, só que do outro lado, discutindo a questão da união estável entre pessoas do mesmo sexo em 1995. Foi um debate muito interessante, inclusive houve um questionamento, à época, do Deputado Severino Cavalcanti, que foi depois Presidente, que perguntou quem era a mulher e quem era o marido entre mim e o David. Daí eu respondi, até de forma muito tranquila, que estávamos aqui discutindo cidadania e não a minha vida privada.

Passaram-se $\mathbf{2 0}$ anos e o Parlamento não se pronunciou, não votou isso. Então, o STF, que respeito muito, é um Poder da nossa República, garante os nossos direitos por omissão deste Congresso Nacional, tanto da Câmara Federal quanto do Senado. Nesse caso o STF não legislou, fez isso simplesmente por omissão. Por isso, é importante que se diga que, para um Estado funcionar, precisa haver Executivo, Legislativo, Judiciário e o poder fiscalizador, que é o Ministério Público. (Toni Reis/ grifos nossos)

O discurso é bonito. O discurso é muito lindo. Nós não estamos aqui para proibir nada, não estamos aqui para proibir ninguém de ser nada, o que está em jogo é a história da civilização humana. Homossexualismo sempre existiu, nós sabemos disso. O que querem é dar um status de família (...) Parlamentares vieram para cá representando uma ideologia cristã ou comunista, não interessa. Essa conversa de Estado laico é a maneira preconceituosa para nos calar, o.k? Se existe o direito de alguém defender a ideologia de Marx aqui, porque não se pode defender uma ideologia baseada em Cristo que, repito, é o paradigma do Ocidente? (Silas Malafaia/ grifos nossos)

O cerne do debate permanece o mesmo. A união estável e o casamento LGBTI+ podem existir como um arranjo familiar tão digno como qualquer outro? Atualmente, a jurisprudência responde positivamente e tais direitos encontram-se assegurados. No entanto, os embates no parlamento e na sociedade permanecem. Ativistas e movimentos conservadores contestam diuturnamente a atuação do STF, considerada por eles um negativo ativismo judicial.

\section{Considerações Finais}

Tudo o que não é proibido é permitido. Essa é a regra geral no direito privado. No entanto, como demonstrado, no Brasil, duas pessoas adultas não poderiam contrair união estável ou matrimônio se fossem do mesmo gênero, mesmo inexistindo norma proibitória. 0 entendimento de que a união estável e o casamento só ocorreriam entre homens e mulheres faziam com que tanto a literatura jurídica quanto a jurisprudência entendessem ser nulo de pleno direito o casamento entre iguais. 
Na Constituinte, o movimento LGBT se concentrou em uma proposta para proibir a discriminação por orientação sexual. Perdeu duas vezes. A proposta não foi aprovada e, quando se debateu a união estável, pela primeira vez se tornou expressa a regra de que ela existiria somente entre homens e mulheres.

A partir do primeiro projeto de lei sobre o tema, em 1995, a pauta ganhou cada vez maior centralidade na atuação dos movimentos sociais. Entretanto, em 2002, uma nova derrota legislativa. Na aprovação do novo Código Civil se fez constar que o casamento se daria apenas entre homens e mulheres.

A preocupação em expressamente proibir traz um aspecto importante na conformação do direito. Quando os atores políticos passaram a ter interesse em normatizar a proibição foi justamente porque a união estável e o casamento passaram a ser uma demanda jurídica. Antes era uma demanda suprimida conforme demonstrado no texto.No processo de positivação de um direito, esta é uma etapa essencial: vencer o silenciamento social e a inviabilização impostos e passar a moldar a demanda como um direito a ser conquistado.

Um outro aspecto demonstrado neste processo e normalmente pouco visibilizado nos estudos jurídicos é a importância dos projetos de lei sobre o tema. Embora nenhum projeto tenha sido aprovado, a tramitação e os debates em tornos deles fizeram com que os atores voluntários neste processo - movimentos LGBTs, parlamentares e juristas aliados - fossem ganhando fôlego, produzindo conhecimento, pautando o debate público e com isso permitindo que novos aliados surgissem e fosse provada a importância de se reconhecer as relações LGBTI+ como constituições familiares.

Ademais, na seara jurisdicional, os atores políticos involuntários que acessaram o Sistema de Justiça não por pautarem a demanda coletivamente, mas por contingências práticas de sua realidade ( a relação existia e era necessário partilhar os bens, por exemplo), foram dando corpo ao debate, especialmente na insistência do uso dasVaras de Família para a resolução da lide.

Os movimentos sociais e ativistas não perderam de vista o potencial do debate pela via jurisdicional e passaram a usar tanto das possibilidades de litigância estratégica perante o Supremo Tribunal Federal como também de processos pioneiros como o pedido de habilitação ao casamento realizado no Rio Grande do Sul em 2009.

A conquista do direito fundamental de ter suas relações afetivas reconhecidas como tão dignas quanto às relações heterossexuais foi uma vitória obtida não só pelo 
movimento LGBTI+ organizado, mas também por cada ator involuntário que se apresentou perante o Sistema de Justiça.

Foi também uma conquista derivada da atuação de todos os aliados e aliadas que permitiram a partir de seus conhecimentos e/ou suas posições estratégicas de poder, o reconhecimento deste direito, fazendo com o que o Estado - este ente que aparenta ser neutro e monolítico, mas não o é - assumisse que o afeto é a base constituinte das relações familiares.

As lições aprendidas em cada umas das batalhas travadas talvez sejam apenas apreensíveis em sua inteireza por seus participantes, mas acreditamos que uma visão narrativa como a apresentada é essencial para sedimentar a concepção de que direitos fundamentais não são dados históricos, nem derivam da natureza humana. Direitos fundamentais são conquistas. Foram assegurados. Podem ser perdidos. Por isso, é tão importante entender a complexidade e os desafios do percurso.

\section{Referências Bibliográficas}

ALMEIDA, Silvio. Racismo Estrutural. 1. ed. São Paulo/ Brasil: Pólen Livros, 2019. 256p.

BARROSO, Luís Roberto. Contramajoritário, Representativo e lluminista: Os papeis dos tribunais constitucionais nas democracias contemporâneas / Countermajoritarian, Representative, and Enlightened: The roles of constitutional tribunals in contemporary democracies. Revista Direito e Práxis, [S.I.], v. 9, n. 4, p. 2171-2228, dez. 2018. ISSN 21798966. Disponível em: <https://www.epublicacoes.uerj.br/index.php/revistaceaju/article/view/30806/21752>. Acesso em: 17 jun. 2020.

BRASIL Câmara dos Deputados. Disponível em: https://www2.camara.leg.br/atividadelegislativa/legislacao/Constituicoes_Brasileiras/constituicao-

cidada/constituintquees/parlamentaresconstituintes/deputados-constituintes Acesso em: 20 de junho de 2019

BRASIL PDL 106/2013. Disponível: https://www25.senado.leg.br/web/atividade/materias/-/materia/112745 Acesso em: 12.06.2020

BRASIL Superior Tribunal De Justiça. RESP 1.183.378/RS Disponível em: https://www.conjur.com.br/dl/resp-1183378-voto-relator-julgamento.pdf Acesso em: 16 de junho de 2020.

BRASIL. Câmara dos Deputados. PDC 1054/2013 Disponível em : https://www.camara.leg.br/proposicoesWeb/fichadetramitacao?idProposicao $=584580$ Aceso em 12 de junho de 2020. 
BRASIL. Câmara dos Deputados. PDC 637/2012 Disponível em: https://www.camara.leg.br/proposicoesWeb/fichadetramitacao?idProposicao=552023 Acesso em: 120/6/2020.

BRASIL. Câmara dos Deputados. PDC 639/2017 Disponível: https://www.camara.leg.br/proposicoesWeb/fichadetramitacao?idProposicao=2132541 Acesso em 12.06.2020.

BRASIL. Assembleia Nacional Constituinte. Disponível em: http://imagem.camara.gov.br/Imagem/d/pdf/sup66anc27mai1987.pdf\#page=127 Acesso em: 30 de junho de 2020.

BRASIL. Assembleia Nacional Constituinte. Disponível em: http://imagem.camara.gov.br/Imagem/d/pdf/sup115anc05ago1987. pdf\#page=87 Acesso em: 30 de junho de 2020.

BRASIL. Câmara dos Deputados. PDC 1054/2013https://www.camara.leg.br/proposicoesWeb/fichadetramitacao?idProposica $0=584580$.

BRASIL. Câmara dos Deputados. Disponível em: https://www2.camara.leg.br/atividadelegislativa/legislacao/Constituicoes_Brasileiras/constituicao-

cidada/constituintes/parlamentaresconstituintes/senadores-constituintes Acesso em: 20 de junho de 2019.

BRASIL. Câmara dos Deputados. Disponível em: https://www2.camara.leg.br/atividadelegislativa/legislacao/Constituicoes_Brasileiras/constituicao-cidada/o-processoconstituinte/lista-de-comissoes-e-subcomissoes Acesso em: 22 de junho de 2019.

BRASIL. Câmara dos Deputados. Disponível em: https://escriba.camara.leg.br/escribaservicosweb/html/39619. Acesso em 15.06.2020

BRASIL. Câmara dos Deputados. Disponível em: https://www.camara.leg.br/proposicoesWeb/prop_pareceres_substitutivos_votos?idPr oposicao=597005 Acesso em: 14.06.2020.

BRASIL. Decreto 7037/2010. Disponível em: http://www.planalto.gov.br/ccivil_03/_ato2007-2010/2009/decreto/d7037.htm Acesso em: 14 de junho de 2020

BRASIL. Decreto 7177/2010 http://www.planalto.gov.br/ccivil_03/_ato20072010/2010/Decreto/D7177.htm\#art1 Acesso em: 14 de junho de 2020 BRASIL. Lei 4121/1962. Disponível em: http://www.planalto.gov.br/CCIVIL_03/LEIS/19501969/L4121.htm Acesso em: 15 de junho de 2020.

BRASIL. Parecer da Relatora na Comissão de Constituição, Justiça e Cidadania (CCJC) ao PL 4754/2016, p. $05 . \quad$ Disponível em: https://www.camara.leg.br/proposicoesWeb/prop_mostrarintegra?codteor=1769130\&f ilename=PRL+3+CCJC+\%3D\%3E+PL+4754/2016 Acesso em 12 de junho de 2020 BRASIL. PL 4914/2009, por José Genoíno (PT), Manuela D'ávila (PCdoB), Maria Helena (PSB), Celso Russomanno (PP), Ivan Valente (PSOL) Fernando Gabeira (PV), Arnaldo Faria 
de Sá (PTB), Solange Amaral (DEM), Marina Maggessi (PPS), Colbert Martins (PMDB), Paulo Rubem Santiago (PDT) e Professora Raquel Teixeira (PSDB). Disponível em: https://www.camara.leg.br/proposicoesWeb/fichadetramitacao?idProposicao=427692 Acesso em: 14 de junho de 2020.

BRASIL.

PL

$634 / 1975$.

https://www.camara.leg.br/proposicoesWeb/fichadetramitacao?idProposicao=15675 Acesso em: 16 de junho de 2020.

BRASIL. Projeto de Lei 1151/1995. Disponível em: http://imagem.camara.gov.br/Imagem/d/pdf/DCD21NOV1995.pdf\#page=41 Acesso em 02 de julho 2019.

BRASIL. Senado Federal. PEC 70/2003. Disponível em: https://www25.senado.leg.br/web/atividade/materias/-/materia/61093 Acesso em: 16 de junho de 2020.

BRASIL. Supremo Tribunal Federal. Acórdão na integra: http://redir.stf.jus.br/paginadorpub/paginador.jsp?docTP=AC\&doclD=628633 Acesso em 09 de julho de 2019.

BRASIL. Supremo Tribunal Federal. Disponível em: https://jurisprudencia.stf.jus.br/pages/search/sjur200017/false Acesso em: 14 de junho de 2020

CONSULTOR JURÍDICO. JULGAMENTO POLÊMICO Justiça gaúcha reconhece união estável entre homossexuais. Disponível em: https://www.conjur.com.br/2003-mai12/tj_gaucho_reconhece_uniao_estavel_entre_homossexuais Acesso em 15 de junho de 2020.

CONSULTOR JURÍDICO. Justiça gaúcha reconhece união estável entre homossexuais Disponível em: https://www.conjur.com.br/2003-mai12/tj_gaucho_reconhece_uniao_estavel_entre_homossexuais Acesso em: 17 de junho de 2020.

COSTA, Dilvanir José da. A família nas Constituições Brasília a. 43 n. 169 jan./mar. 2006 Disponivel em: http://www2.senado.leg.br/bdsf/bitstream/handle/id/92305/Costa\%20Dilvanir.pdf?seq uence=6\&isAllowed=y Acesso em 15 de junho de 2020.

CPDOC/FGV. Disponível em: http://www.fgv.br/cpdoc/acervo/dicionarios/verbetetematico/assembleia-nacional-constituinte-de-1987-88 Acesso em: 20 de junho de 2019.

CPDOC/FGV. Disponível em: http://www.fgv.br/cpdoc/acervo/dicionarios/verbetetematico/assembleia-nacional-constituinte-de-1987-88 Acesso em: 22 de junho de 2019.

CUNHA, M. F. (2017). Casamentos mistos: entre a escravidão e a liberdade Franca-São Paulo/Brasil, século XIX. Revista Brasileira De Estudos De População, 34(2), 223-242. https://doi.org/10.20947/S0102-3098a0022. 
DIAS, Maria Berenice. Homoafetividade: o que diz a Justiça! Porto Alegre: Livraria do Advogado, 2003.

FIGUEIREDO, Ivanilda. Terror Colorido. Disponível em: https://oglobo.globo.com/opiniao/artigo-terror-colorido-24433466 Acesso em: 29 de maio de 2020.

FOLHA DE SÃO PAULO. https://www1.folha.uol.com.br/fsp/mundo/ft1907200106.htm ; https://www1.folha.uol.com.br/fsp/mundo/ft1601200214.htm; https://www1.folha.uol.com.br/fsp/mundo/ft1606200311.htm Acesso em 17 de junho de 2020.

HOWES, Robert. João Antônio Mascarenhas (1927-1998): pioneiro do ativismo homossexual no brasil. Disponível em: https://www.ifch.unicamp.br/ojs/index.php/ael/article/view/2516/1926

LIFSHITZ, Sebastien. The Invisibles: Vintage Portraits of Love and Pride. Gay Couples in the Early Twentieth Century. New York: Rizzoli , 2014, 144p. E TREVISAN, João Silvério. Devassos no Paraíso. São Paulo: Objetiva, 2018, 555p.

LORDE, Audre. Irmã Outsider. São Paulo: autêntica, 2019, p. 147.

MBEMBE, Achille para interpretar a pulsão de morte social transformada em política de morte. Ver mais: https://revistas.ufrj.br/index.php/ae/article/view/8993/7169].

MISKOLCl, Richard. Pânicos morais e controle social: reflexões sobre o casamento gay. Cad. Pagu [online]. 2007, n.28, pp.101-128. ISSN 1809-4449. https://doi.org/10.1590/S0104-83332007000100006.

MOREIRA, A. J. Cidadania Sexual: Estratégia para Ações Inclusivas. 1. ed. São Paulo: Arraes Editores, 2017. v. 1, 308p.

Recurso Especial no 154.857 - 6a Turma, Relator Ministro Vicente Cernicchiaro, DJ 26.10.1998).

RIOS, R. R. A justiça e os direitos de gays e lésbicas - jurisprudência comentada. Porto Alegre: Sulina, 2003.

SANTOS, Boaventura de Souza. Para uma Revolução Democrática da Justiça. São Paulo: Cortez, 2007, p. 23.

SARLET, I. W. Dignidade da Pessoa Humana e Direitos Fundamentais na Constituição Federal de 1988. 1. ed. Porto Alegre: Livraria do Advogado, 2001. v. 1. 152p.

SARMENTO, Daniel. Livres e Iguais: Estudos de Direito Constitucional. Rio de Janeiro: Lumen Juris, 2006. 308p.

SOUTH AFRICA. Prohibition of Mixed Marriages e Immorality Act, ambas leis de 1949. A primeira proibia o casamento, a segunda as relações sexuais. Disponível em: 
https://www.sahistory.org.za/dated-event/prohibition-mixed-marriages-actcommences Acesso em: 09 de junho de 2020.

STF. Petição 1984-9. Disponível em: http://www.stf.jus.br/portal/cms/verNoticiaDetalhe.asp?idConteudo=60059 Acesso em: 17 de junho de 2020.

UNITED STATES. Supreme Court. Decisão na íntegra disponível em: https://www.oyez.org/cases/1966/395 Acesso em: 09 de junho de 2020.

UNITED STATES. Supreme Court. United States versus Windsor. Decisão na integra: https://www.supremecourt.gov/opinions/12pdf/12-307_6j37.pdf Acesso em: 29 de maio de 2020.

VECHIATTI, Paulo Robert lotti. Manual da Homoafetividade; São Paulo: Método, 2013, p. 158-161. Moreira, A. J. Cidadania Sexual: Estratégia para Ações Inclusivas. 1. ed. São Paulo: Arraes Editores, 2017. v. 1. 308p.

VILALON, Eduardo Martins de Azevedo. O Movimento Homossexual Brasileiro na Constituinte De 87-88: Apontamentos Iniciais sobre As Discussões Na Subcomissão Dos Negros, Populações Indígenas, Pessoas Deficientes e Minorias Disponível em: https://anaiscongressodivsex.files.wordpress.com/2015/03/49-eduardo-vilalon.pdf Acesso em: 07 de julho de 2019.

WARNER, Michael. The Trouble with Normal: Sex, Politics, and the Ethics of Queer Life. Boston: Harvard University Press/New Ed edition, 1999, 227p.

Sobre a autora

\section{Ivanilda Figueiredo}

Professora Adjunta de Direito e Pensamento Político e de Direitos Humanos da Faculdade de Direito da Universidade do Estado do Rio de Janeiro, (FDIR/UERJ), coordenadora da URDIR (Universidade, Resistência e Direitos Humanos) do Núcleo de Direitos Humanos da UERJ e diretora do Centro de Estudos e Pesquisa no Ensino do Direito da UERJ (CEPED/UERJ). E-mail: ivanilda.figueiredo@gmail.com

A autora é a única responsável pela redação do artigo. 